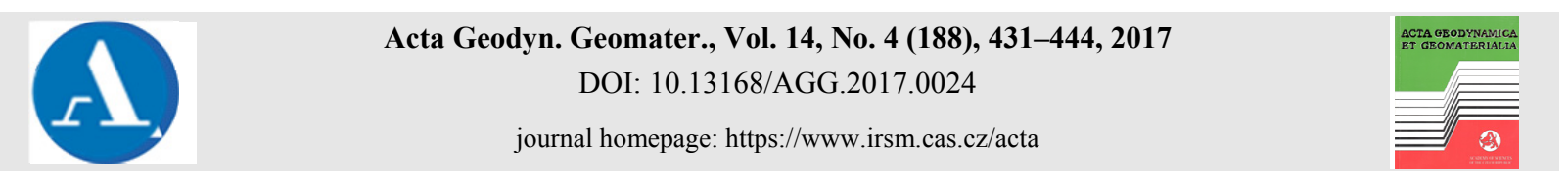

ORIGINAL PAPER

\title{
SINGLE- AND MULTI-COMPONENT INVERSION OF RAYLEIGH WAVES ACQUIRED BY A SINGLE 3-COMPONENT GEOPHONE: AN ILLUSTRATIVE CASE STUDY
}

\author{
Giancarlo DAL MORO ${ }^{1{ }^{1} *}$ and Luca Maria PUZZILLI ${ }^{2)}$ \\ 1) Department of Seismotectonics, Institute of Rock Structure and Mechanics, Czech Academy of Sciences, V Holešovičkách 94/41, \\ 18209 Prague 8 - Czech Republic \\ 2) Department for the Geological Survey of Italy, Italian National Institute for Environmental Protection and Research-ISPRA, \\ via V. Brancati 60, 00144 Rome - Italy \\ *Corresponding author's e-mail: dalmoro@irsm.cas.cz
}

\section{ARTICle INFO}

\section{Article history}

Received 5 July 2017

Accepted 18 September 2017

Available online 23 October 2017

\section{Keywords:}

Surface wave analysis

Rayleigh wave dispersion

Joint inversion

HVSR

Vs30

Full Velocity Spectrum (FVS) inversion

Radial-to-Vertical Spectral Ratio (RVSR)

Rayleigh-wave Particle Motion (RPM)

Passive seismics

Active seismics

\begin{abstract}
Rayleigh wave propagation can occur according to complex mode excitation such that the interpretation of the phase or group velocity spectra can be erroneous thus leading to wrong reconstruction of the subsurface shear-wave velocity profile.

In this paper, we present a case study solved by considering the holistic analysis of the Rayleigh waves recorded by a single 3-component $(3 \mathrm{C})$ geophone and inverted by considering the groupvelocity spectra of the radial and vertical components together with the Radial-to-Vertical Spectral Ratio (RVSR) and the RPM (Rayleigh-wave Particle Motion) frequency curve.

In order to test the performance of the adopted methodologies, we intentionally considered a complex site characterized by a high level of background noise and a limited space for the data acquisition.

In addition, passive data collected by the same $3 \mathrm{C}$ geophone are used to compute the Horizontalto-Vertical Spectral Ratio (HVSR). Due to the vibrations produced by a nearby excavator, in order to obtain a meaningful HVSR we selected only a small portion of the recorded data. Computed HVSR is then jointly inverted with the active data to further validate the retrieved subsurface model and obtain information about the shear-wave velocities of the deeper layers. Altogether, four different inversion strategies are pursued and the obtained $\mathrm{V}_{\mathrm{S}}$ profiles compared also with the results from a local penetrometer test and some borehole data.
\end{abstract}

\section{INTRODUCTION}

Very often, surface waves are acquired and analyzed by considering only the vertical component of Rayleigh waves. The shear-wave velocity (Vs) profile of the investigated site is then typically obtained through the inversion of a user-picked modal dispersion curve (e.g. Park et al., 1999; Xia et al., 1999; Xia, 2014). Figure 1 summarizes the standard procedure for the acquisition and analysis of a multichannel active seismic record used for the so-called Multi-Channel Analysis of Surface Waves, MASW (e.g., Park et al., 1998). A series of regularly-spaced vertical geophones are deployed along a straight line and a vertical-impact source (for instance a sledgehammer or a weight drop) is used to generate Rayleigh waves (Fig. 1a). The recorded seismic traces (Fig. 1b) are then transformed into the velocityfrequency domain so to obtain the phase velocity spectrum (Fig. 1c). In the classical approach, the velocity spectrum is interpreted in terms of modal dispersion curves (the lines in the $\mathrm{A}$ and $\mathrm{B}$ boxes of Fig. 1c) that are interpreted, picked and inverted to eventually obtain the $\mathrm{V}_{\mathrm{S}}$ vertical profile (Fig. 1d).

Unfortunately, since Rayleigh waves can propagate according to very complex mode combinations, it is sometimes quite hard or impossible to correctly identify and separate specific modal dispersion curves. Misinterpretation of modal curves necessarily leads to erroneous $\mathrm{V}_{\mathrm{S}}$ profiles (e.g. Zhang and Chan, 2003). In concrete terms, we should for instance address the following question: how can we verify and demonstrate that the signals highlighted in Figure 1c actually pertain to the fundamental mode and to the first overtone?

Indeed, the seemingly simplicity of a continuous signal in the velocity spectrum does not necessarily mean that that signal pertains to a single mode: this for instance means that the signal in the box $B$ (Fig. 1c) does not necessarily relate to a single higher mode. A series of synthetic and real data sets aimed at giving evidence of these aspects are presented in Dal Moro (2014 - Chapter 3) and Dal Moro et al. (2017a).

A possible solution to these problems and ambiguities can be represented by the joint acquisition and analysis of Love waves and/or the radial component of Rayleigh waves (Safani et al., 2005; Dal Moro and Ferigo, 2011; Xia et al., 2012; Dal Moro et al., 2015b, 2016, 2017a). 
a)
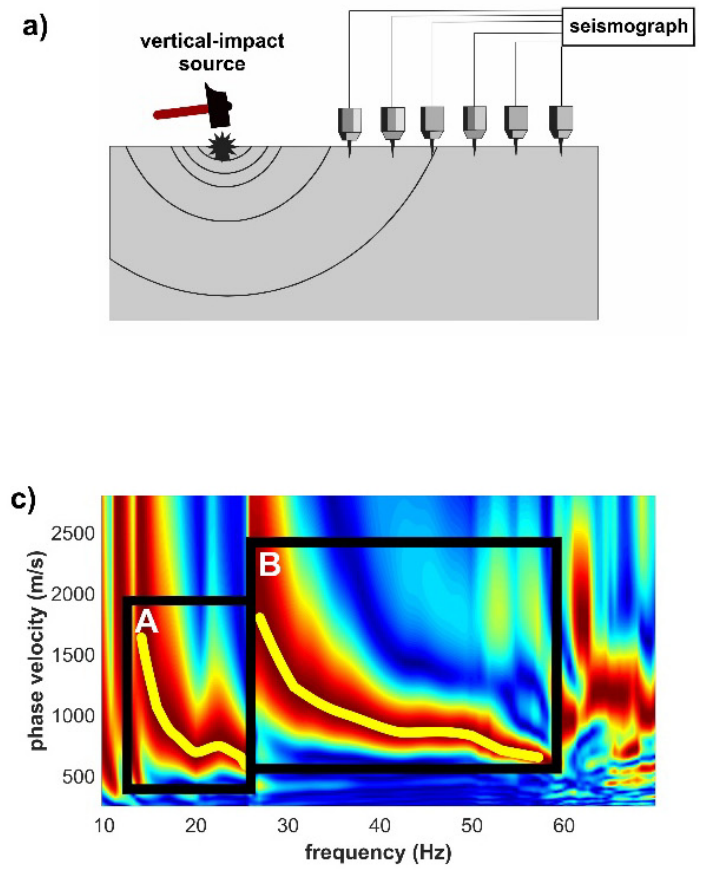

b)

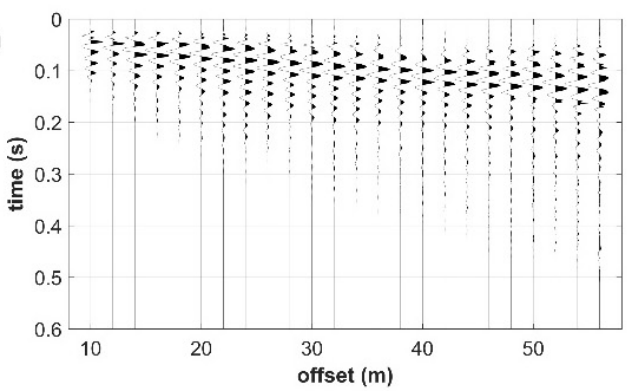

d)

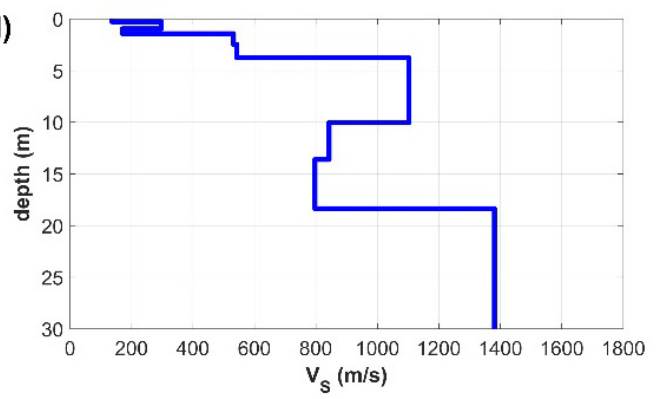

Fig. 1 Acquisition and processing of Rayleigh waves according to the standard MASW approach: a) a series of vertical-component geophones are deployed and a vertical-impact source is used to produce Rayleigh waves; b) a multi-channel (vertical component) dataset is obtained; c) seismic traces are transformed into the velocity-frequency domain in order to obtain a phase-velocity spectrum which is then interpreted in terms of modal dispersion curves; d) $\mathrm{V}_{\mathrm{S}}$ profile obtained by inverting the interpreted dispersion curves. A wrong interpretation of the signals in the velocity spectrum necessarily leads to an erroneous $V_{S}$ profile.

A further possibility that, thanks to the light field procedures and necessary equipment, can be an appealing and efficient solution, is represented by the holistic approach presented in Dal Moro (2014) and Dal Moro et al. (2015b, 2015c, 2015d, 2016, 2017a) [Holistic analysis of Surface waves - HS]. This holistic methodology is an improvement of the classical Multiple Filter Analysis (MFA) technique described in Dziewonsky et al. (1969) and is based on the active data recorded by means of a single 3component (3C) geophone.

For the present work, we followed this latter approach, also considering and discussing the Rayleigh-wave Particle Motion (RPM) frequency curve (Dal Moro et al., 2017b) and the Horizontal-toVertical Spectral Ratio (HVSR, e.g. Fäh et al., 2001).

In order to illustrate the methodology, we intentionally chose a challenging site with conditions far from ideal. During the survey, there were in fact ongoing earthworks responsible for a high level of background noise. Furthermore, the space available for the seismic-data acquisition was very limited.

The obtained shear-wave velocity profiles were eventually compared with the data from a penetrometer test performed in the same area and with some borehole information available from a nearby site.

\section{DATA ACQUISITION AND INVERSION PROCEDURES}

The active data were acquired by means of a single $3 \mathrm{C}$ geophone according to the field procedure described for instance in Dal Moro et al. (2015b, 2015c, 2015d, 2016) and briefly summarized in Figure 2. When a vertical-impact source is applied, the vertical and radial geophones record the vertical $(\mathrm{Z})$ and radial (R) components of the generated Rayleigh waves. On the other side, in case a shear source is adopted, the produced Love waves are recorded along the $\mathrm{T}$ component.

For the present work, we only consider Rayleigh waves, so just the $\mathrm{Z}$ and $\mathrm{R}$ components.

We considered four objects for the holistic (i.e. joint) analysis of Rayleigh waves:

1. the group-velocity spectrum of the $\mathrm{Z}$ component;

2. the group-velocity spectrum of the R component;

3. the Radial-to-Vertical Spectral Ratio (RVSR), defined as the ratio between the amplitude spectra of the vertical and radial components;

4. the Rayleigh-wave Particle Motion (RPM) curve describing the actual motion of Rayleigh waves.

This latter curve (the RPM frequency curve) was recently introduced in Dal Moro et al. (2017b) and aims at quantitatively describing the particle motion as a function of the frequency. Rayleigh waves, in fact, can propagate not according to a retrograde motion (as often simplistically believed) but as a complex mix of retrograde and prograde motion (see also Tanimoto and Rivera, 2005; Malischewsky et al., 2008). The RPM frequency curve represents the correlation coefficients (frequency by frequency) between the radial component and the Hilbert transform of the vertical component. A purely retrograde motion is defined by a +1 value, whereas 


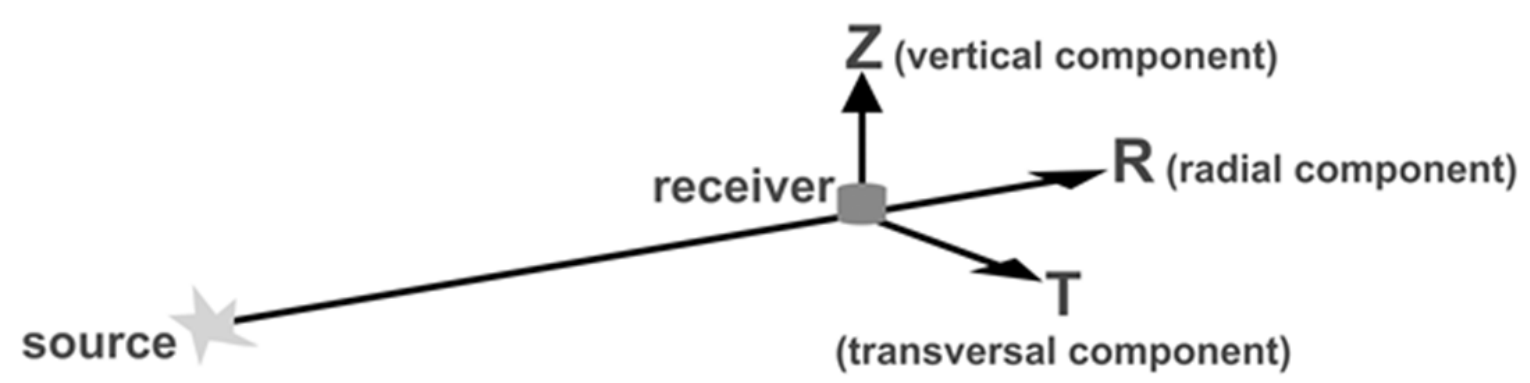

Fig. 2 Data acquisition according to the active HS methodology: one source and one 3C receiver set at a fixed distance (offset) from the source. For the present study we considered Rayleigh waves only, so just the vertical $(\mathrm{Z})$ and radial $(\mathrm{R})$ components.

a purely prograde motion has a -1 value. Since the real motion is often a complex combination of various components, the actual values range between -1 and +1 .

The same 3C geophone has been used to acquire passive data useful for instance to define the HVSR curve.

It must be underlined that the group-velocity spectra considered for the analysis are not interpreted in terms of modal dispersion curves but are processed according to the Full Velocity Spectrum (FVS) approach, thereby going beyond the subjectivity related to the picking of modal dispersion curves.

The FVS approach relies on the analysis (inversion) of the whole velocity spectrum (or spectra, in case of multi-component analysis) and not on interpreted dispersion curves and is accomplished in three main steps (Dal Moro, 2014; Dal Moro et al. 2015a, 2016):

1. computation of the synthetic traces of the considered component(s) for a tentative model;

2. determination of the velocity spectrum/a of the synthetic traces computed in the previous step;

3. computation of the misfit(s) between the field velocity spectrum/a and the synthetic one(s).

These three steps are implemented within a heuristic optimization scheme that minimizes the misfit(s), thus eventually providing the subsurface model having the velocity spectrum as close as possible to the velocity spectrum of the field data. When two or more components are jointly analyzed, the adopted inversion scheme is based on the Pareto optimality which aims at finding the models that represent the best compromise with respect to the two (or more) considered objective functions (Dal Moro and Pipan, 2007). Such inversion procedure belongs to the family of multi-objective optimization schemes (Sarawagi et al., 1985; Zitzler and Thiele, 1999; Van Veldhuizen and Lamont, 1998; Coello Coello, 2003; Dal Moro and Pipan, 2007; Dal Moro and Ferigo, 2011).

It must be emphasized that a joint inversion is always necessarily a sort of compromise. In other words, it is usually quite hard to perfectly match all the objects, especially when the data are noisy and lateral variations occur. In fact, the different components can respond differently to non-ideal conditions and to the various kinds of coherent and incoherent noise that characterize the site (e.g. Rodríguez-Castellanos et al., 2006).

\section{THE GRADO-MARANO LAGOON CASE STUDY}

The investigated site is located in the centralwestern area of the Grado-Marano lagoon (Northern East Italy - Fig. 3). A series of works aimed at improving the local hydraulic infrastructures required the definition of the local stratigraphy both in geotechnical terms as well as with respect to the Vs profile. A non-standard approach was required due to:

1. the limited space available (Fig. 3);

2. the significant noise produced by the earthworks going on in the area (Fig. 4).

Active data were acquired according to the parameters reported in Table 1 and using a $2 \mathrm{~Hz} 3 \mathrm{C}$ geophone equalized by means of an inverse filter (e.g. Bertram and Margrave, 2011) so to be able to properly define the amplitude down to about $0.3 \mathrm{~Hz}$. Because of the noisy background due to the activities of the excavator (Fig. 4), we acquired 17 shots, then removing the first three shots (characterized by a low signal-to-noise ratio) and stacking just 14 shots (Fig. 5).

From the obtained stacked data of the $\mathrm{Z}$ and $\mathrm{R}$ components (Fig. 6a), we defined four objects used for the joint inversion aimed at retrieving the vertical $\mathrm{V}_{\mathrm{S}}$ profile: the Radial-to-Vertical Spectral Ratio (Fig. 6b), the two group-velocity spectra reported in Figures $6 \mathrm{c}$ and $6 \mathrm{~d}$ and the Rayleigh-wave Particle Motion (RPM) frequency curve reported in Figure 7.

The values (i.e. the frequency-velocity matrix) reported in Figures $6 \mathrm{c}$ and $6 \mathrm{~d}$ are normalized frequency by frequency so to easily identify the group velocities for each frequency regardless of the amplitude of each specific frequency, which clearly depends on the characteristics of the adopted source

Table 1 Acquisition parameters for the active data (see also Fig. 3).

\begin{tabular}{lc}
\hline offset & $30 \mathrm{~m}$ \\
sampling interval & $1 \mathrm{~ms}$ \\
record time & $2 \mathrm{~s}$ (then cut to 1) \\
source & $8 \mathrm{~kg}$ sledgehammer \\
stack & 14 \\
\hline
\end{tabular}




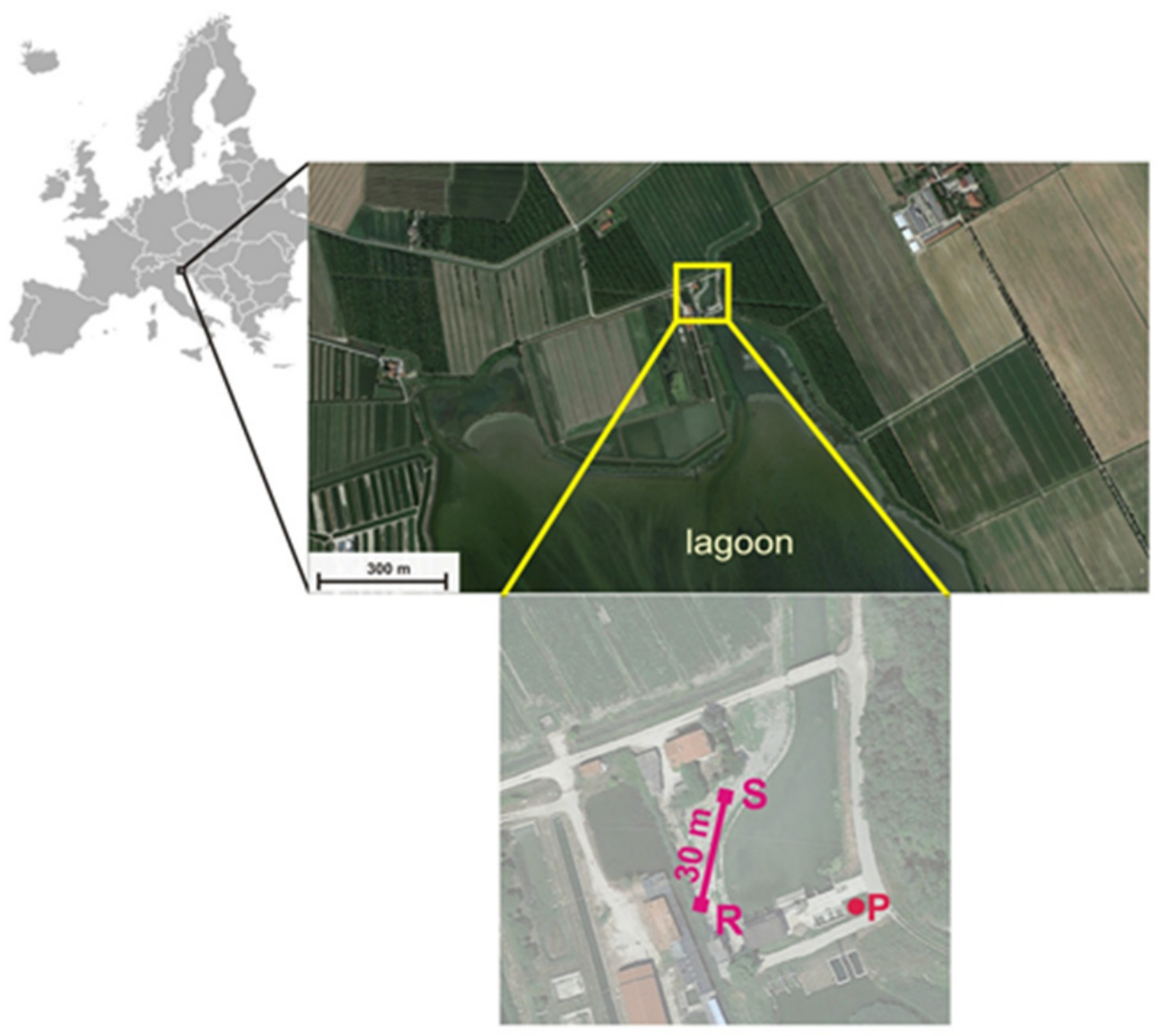

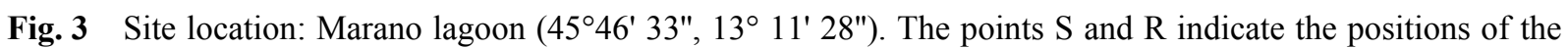
Source and Receiver during the HS acquisition (see also Table 1). The point $\mathrm{P}$ corresponds to the location of the penetrometer test.

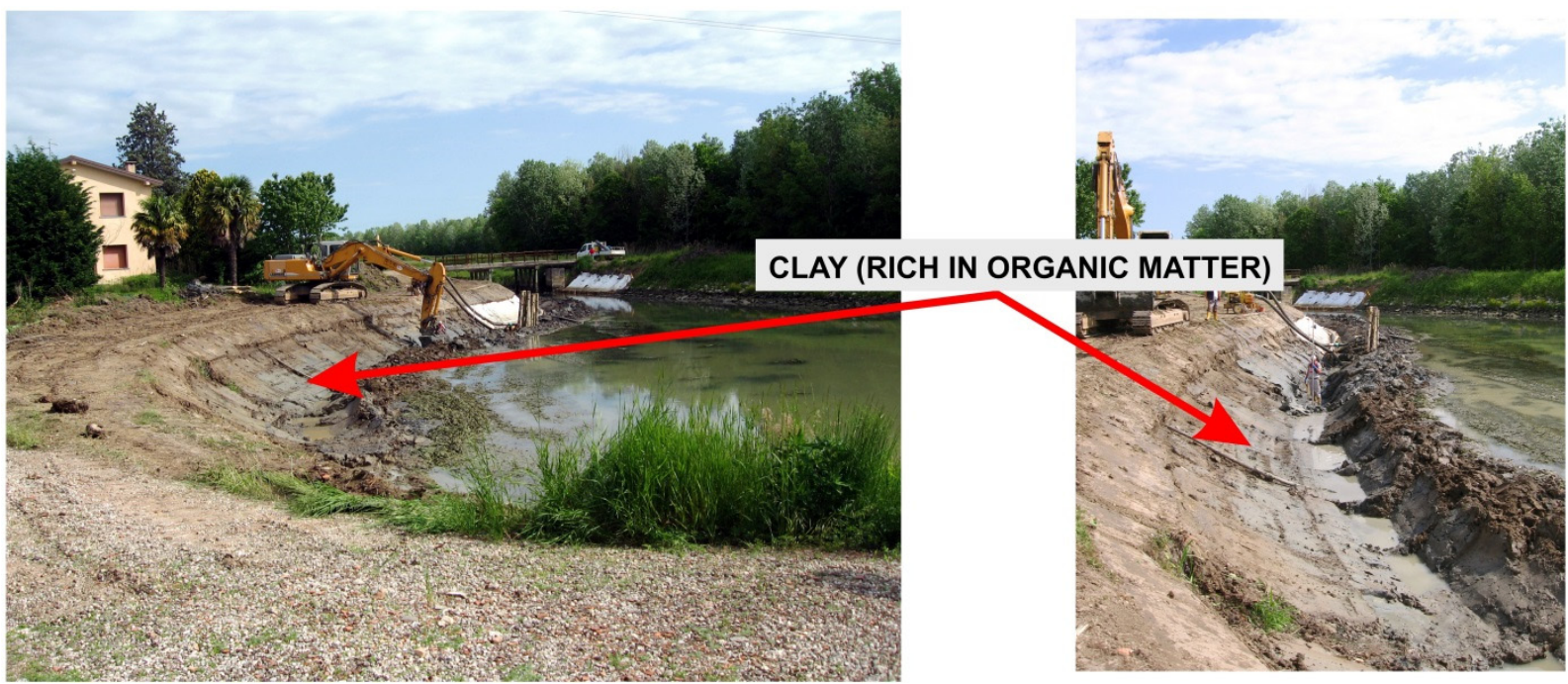

Fig. 4 Two pictures of the area during the seismic survey. The arrows point to the greyish blue clay (quite rich in organic matter) below a superficial clay layer of about $1 \mathrm{~m}$. Also visible the excavator at work during the acquisition of the seismic data. 

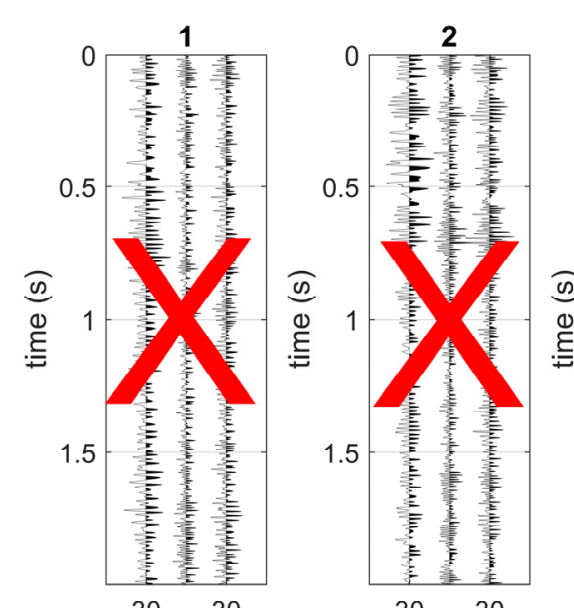

1.5

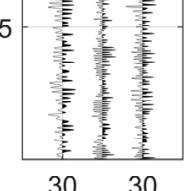

offset (m)
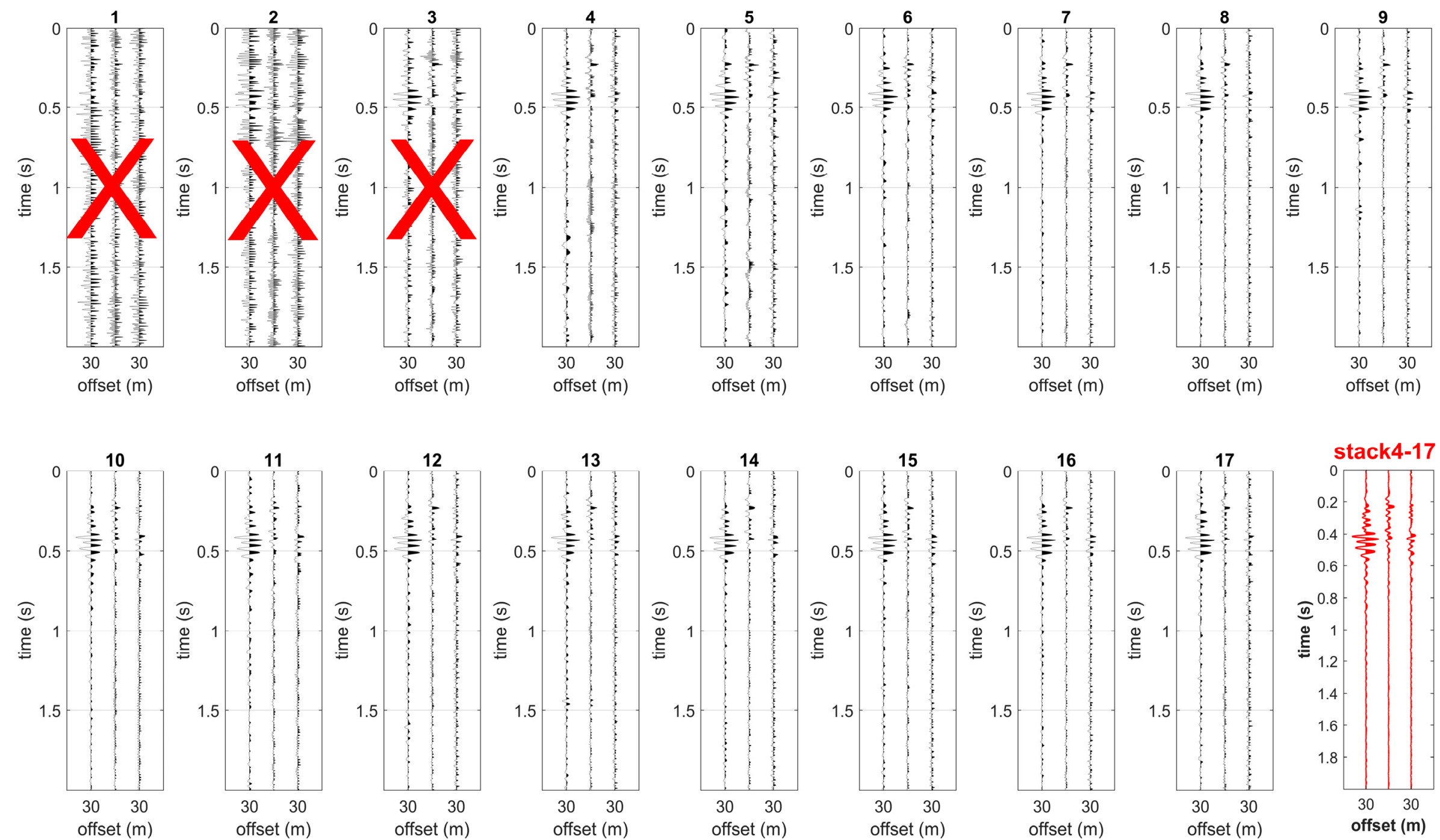

Fig. 5 The 17 recorded shots (vertical-impact force): due to poor quality, the first three shots were removed so to obtain a stacked dataset (reported in the lower-right corner) with a higher signal-to-noise ratio. The three traces refer to the vertical, radial and transversal components, respectively (in the present study the transversal component is not considered) 
a)

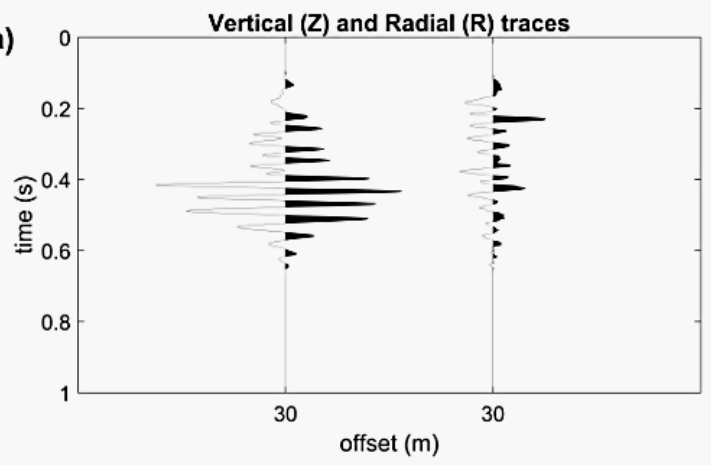

c)

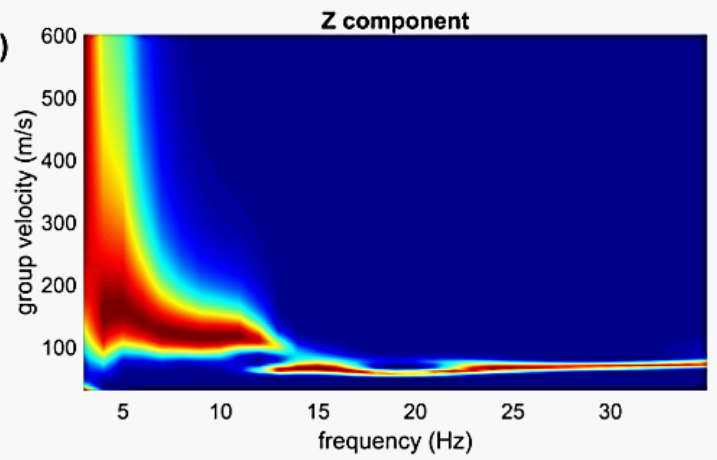

b)

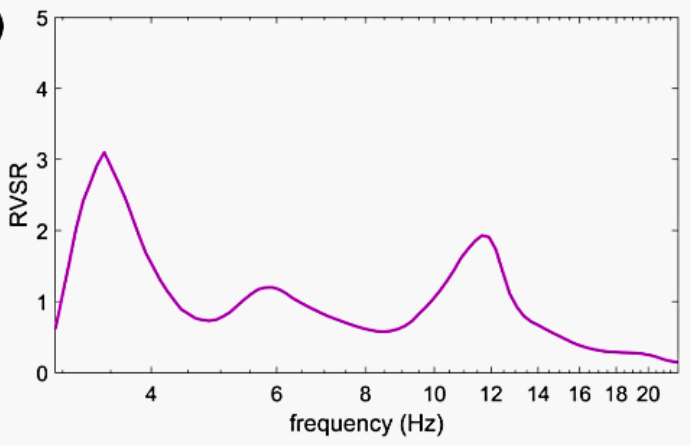

d)

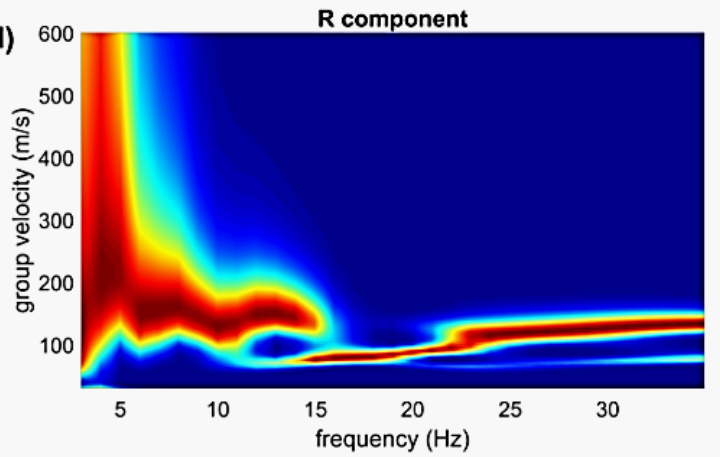

Fig. 6 Field data: a) vertical $(Z)$ and radial (R) field traces (relative amplitude scale preserved); b) the RVSR curve; c) group-velocity spectrum of the $\mathrm{Z}$ component; d) group-velocity spectrum of the $\mathrm{R}$ component.

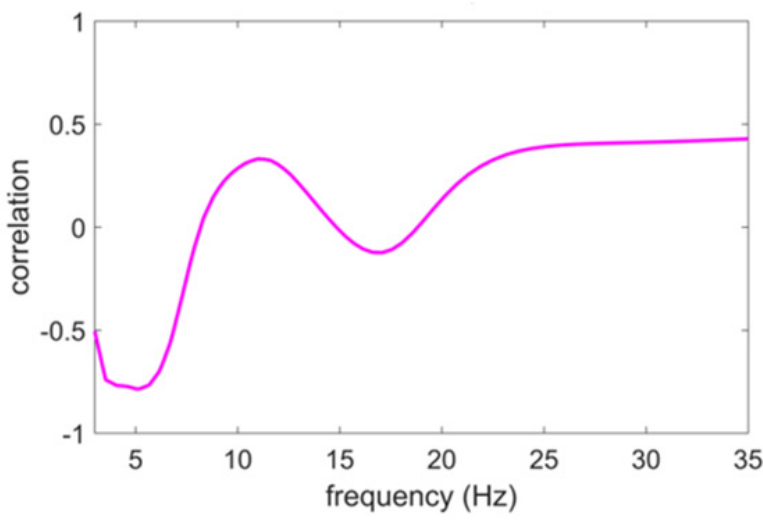

Fig. 7 Rayleigh-wave Particle Motion (RPM) frequency curve computed for the field data (Fig. 6a) according to the methodology described in Dal Moro et al. (2017).

and on the attenuation produced by the soil properties. Such normalization is applied also to the synthetic spectra so not to influence the inversion process which is then focused on the group velocities only, independently on the amplitude spectrum of the wavelet.

In the following sections, we present the joint inversions performed according to the procedure described in Dal Moro (2014) and Dal Moro et al. $(2015 b, 2015 c)$. The obtained results are also compared with the $\mathrm{V}_{\mathrm{S}}$ profile obtained by inverting only one component. Because of the complex distribution of energy among apparently-different modes, in this case we chose the group-velocity spectrum of the radial component (compare Figs. 6c and $6 \mathrm{~d})$.

Eventually, in order to obtain information about deeper layers, we also included the microtremor data (used to define the HVSR curve) which, because of the noise produced by the excavator, required some careful data selection.

Four different inversion procedures are then considered:

1. joint inversion of the $\mathrm{Z}$ and $\mathrm{R}$ group-velocity spectra together with the RVSR curve;

2. joint inversion of the $\mathrm{Z}$ and $\mathrm{R}$ group-velocity spectra together with the RPM frequency curve;

3. inversion of the R group-velocity spectrum alone; 4. joint inversion of the $\mathrm{Z}$ and $\mathrm{R}$ group-velocity spectra together with the HVSR curve.

\subsection{GROUP-VELOCITY SPECTRA (Z AND R) AND RVSR}

The results of the inversion performed considering the $\mathrm{Z}$ and $\mathrm{R}$ group velocity spectra and the RVSR curve are summarized in Figures 8 and 9. The Vs profiles in Figure 9 highlight the presence of a soft-sediment cover also clearly visible along the river bank (Fig. 4). The obtained $\mathrm{V}_{\mathrm{S}}$ profile is shown down to $30 \mathrm{~m}$ even if, because of the limited offset (30 $\mathrm{m}$ - see Table 1 and Fig. 3), the actual penetration depth can be estimated to be about 15-20 m (i.e. half or two thirds of the adopted offset). In spite of this, 

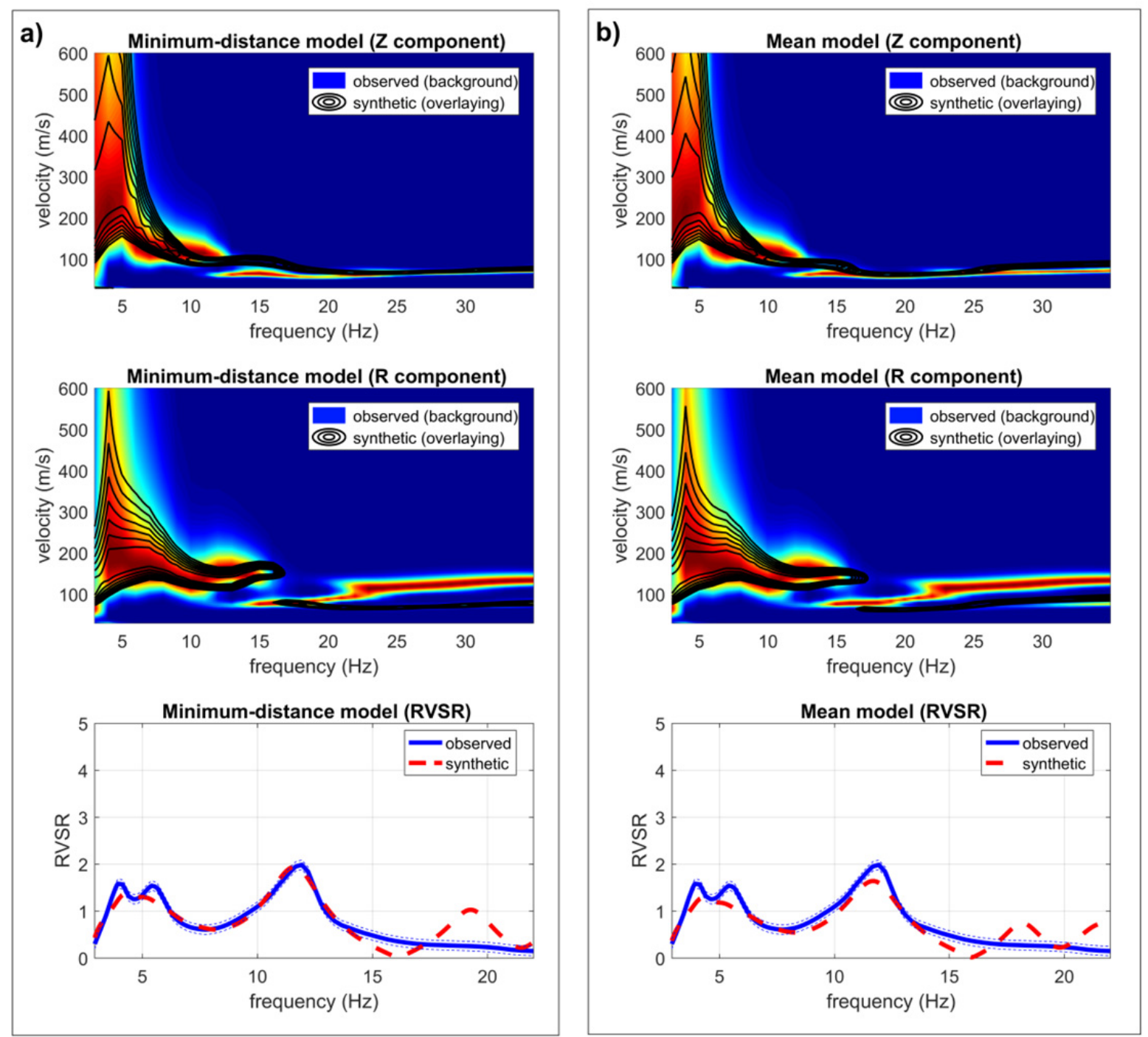

Fig. 8 Joint HS inversion considering the $Z$ and R group velocity spectra and the RVSR curve. Shown the data pertaining to the two final most important models (see also Fig. 9): a) minimum-distance model; b) mean model computed from all the Pareto-front models. Background colours represent the field data velocity spectra while the overlaying black contour lines the synthetic data.

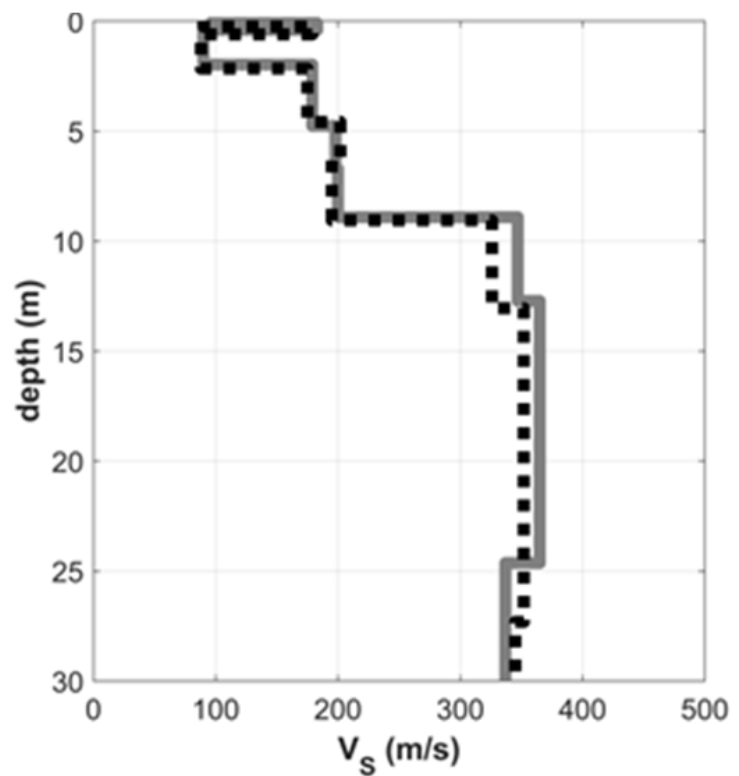

Fig. $9 V_{S}$ profiles of the two most important final models considered in Figure 8 (mean model: dotted line; minimum-distance model: continuous gray line). since the $V_{S}$ profiles obtained by means of the four considered inversion strategies will be eventually compared, we present the $\mathrm{V}_{\mathrm{S}}$ profile down to $30 \mathrm{~m}$ for all the four considered cases, although the only inversion that can actually provide information about the deeper layers is the forth one (joint inversion of the $Z$ and $R$ group-velocity spectra and the HVSR curve - see 3.4 section).

The higher Vs values $(>300 \mathrm{~m} / \mathrm{s})$ at a depth of about $10 \mathrm{~m}$ can be associated to sandy deposits welldocumented in the area (some geotechnical data will be presented in the Discussion paragraph).

\subsection{GROUP-VELOCITY SPECTRA (Z AND R) AND RPM FREQUENCY CURVE}

The results of the joint inversion of the $\mathrm{Z}$ and $\mathrm{R}$ group velocity spectra and the RPM frequency curve are presented in Figures 10 and 11. In general terms, the obtained $V_{S}$ profiles are similar to those reported in the previous section, and the transition between the soft $10 \mathrm{~m}$ cover and the deeper sediments 

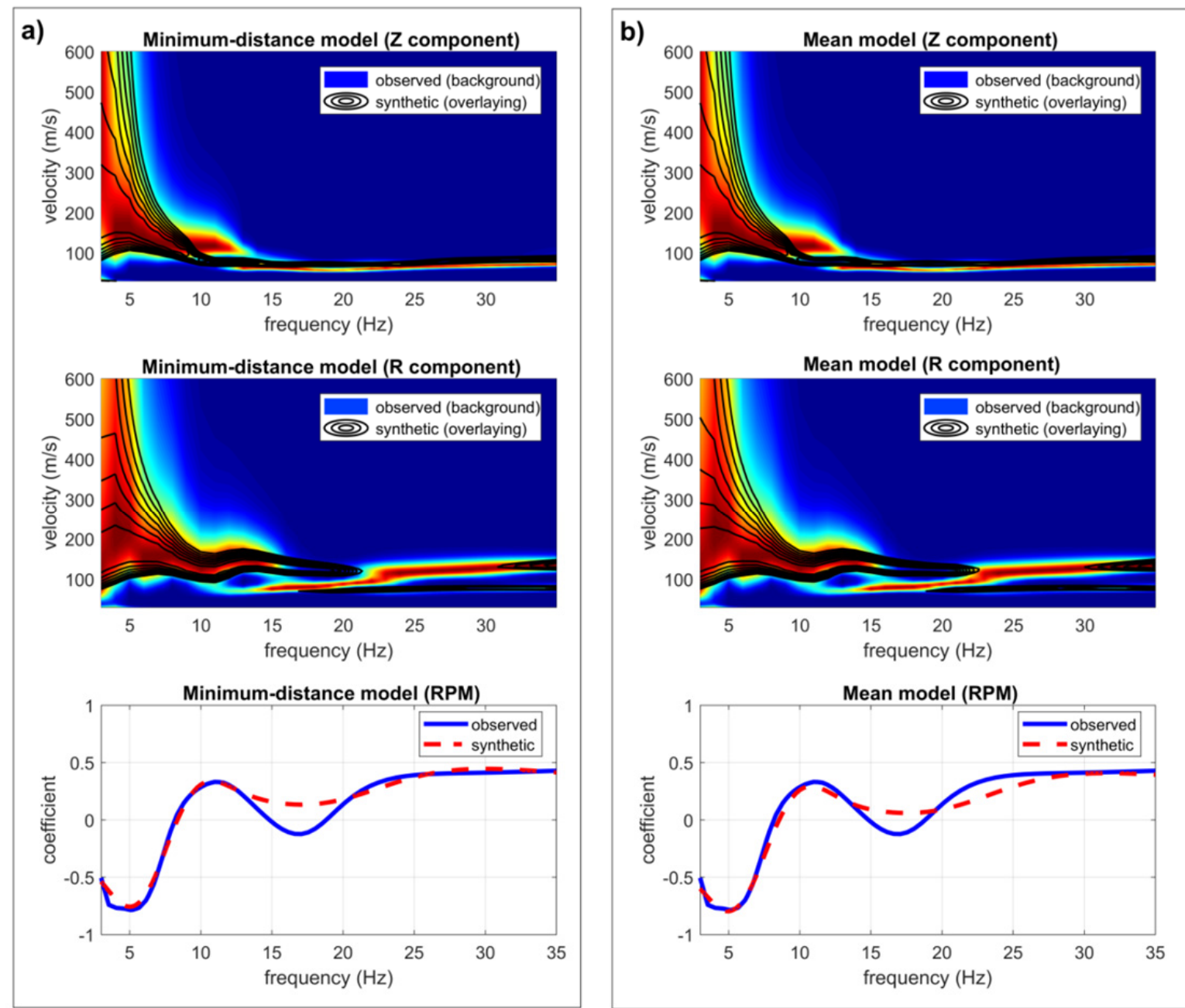

Fig. 10 Joint HS inversion considering the $Z$ and $R$ group velocity spectra and the RPM frequency curve. Shown the data pertaining to the two final most important models (see also Fig. 11): a) minimum-distance model; b) mean model computed from all the Pareto-front models. Background colours represent the field data velocity spectra while the overlaying black contour lines the synthetic data.

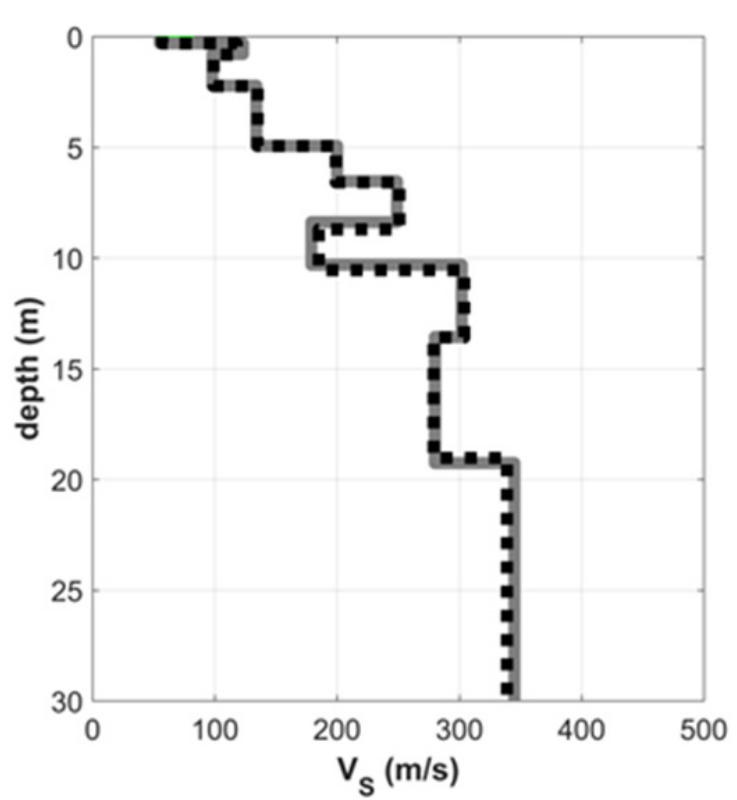

Fig. $11 \mathrm{~V}_{\mathrm{S}}$ profiles of the two most important final models considered in Figure 10 (mean model: dotted line; minimum-distance model: continuous gray line). (characterized by $\mathrm{V}_{\mathrm{S}}$ around $300 \mathrm{~m} / \mathrm{s}$ ) is clear in both the cases.

\subsection{SINGLE-COMPONENT INVERSION: GROUP- VELOCITY SPECTRUM OF THE RADIAL COMPONENT}

The result of the FVS inversion of the groupvelocity spectrum of the radial component is summarized in Figure 12 (the best and mean models are computed considering the procedure described in Dal Moro et al., 2007). In this case the match between the field and synthetic group-velocity spectra is so-tospeak "perfect" but, from the conceptual point of view the solution (the Vs profile) is less robust (see also Dal Moro et al., 2015d).

In general terms, the obtained $\mathrm{V}_{\mathrm{S}}$ profiles show again the evidence of a $10 \mathrm{~m}$ soft-sediment cover over a sandy (stiffer) layer.

It is anyway interesting to point out the relatively-stiffer layer at a depth of about $7 \mathrm{~m}$, which is also identified by the $\mathrm{Z}+\mathrm{R}+\mathrm{RPM}$ inversion presented in the 3.2 section and that will be briefly commented in the Discussion paragraph. 
a)

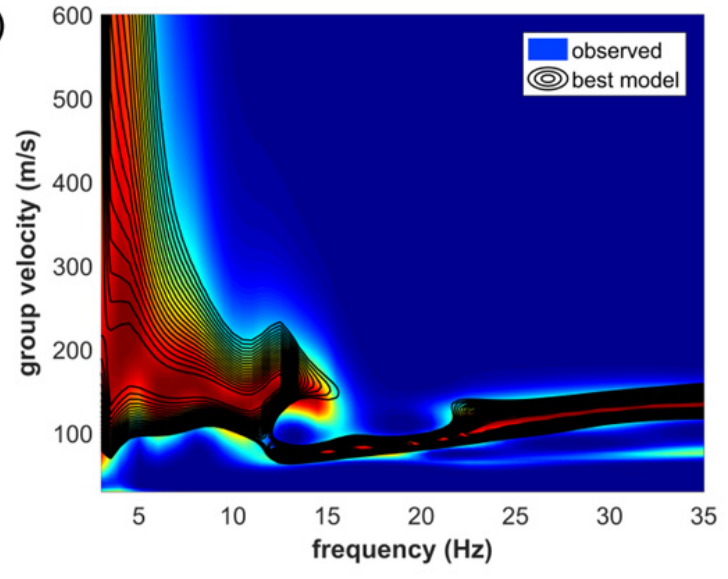

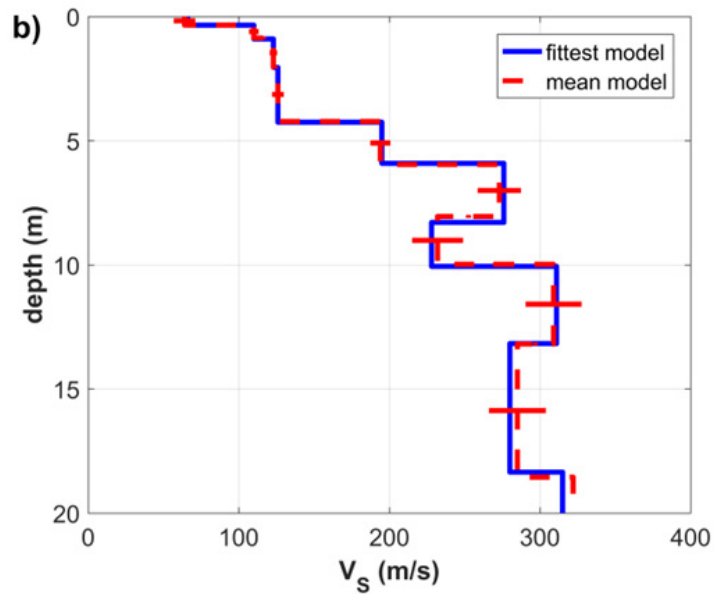

Fig. 12 FVS inversion of the group-velocity spectrum of the radial component: a) field (background colours) and synthetic (overlaying black contour lines) group-velocity spectra; $b$ ) obtained $\mathrm{V}_{\mathrm{S}}$ profiles (reported the fittest and the mean model).

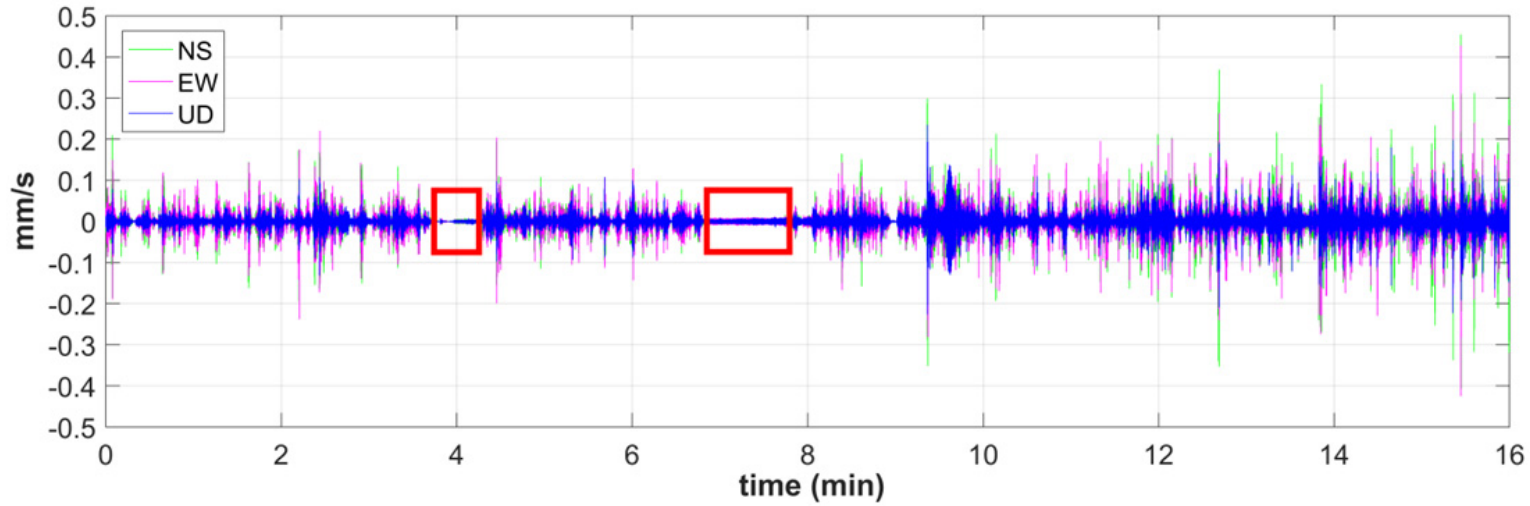

Fig. 13 Passive data recorded with the aim of determining the HVSR curve. The large amplitudes of the vibrations produced by the excavator about $40 \mathrm{~m}$ away from the geophone position (see Figs. 3 and 4) can seriously influence and distort the HVSR. The two rectangles highlight two moments (about $1.5 \mathrm{~min}$ ) during which the excavator temporarily stopped working. The amplitude spectra and HVSR curves of the raw and selected data are reported in Figures 14 and 15, respectively.
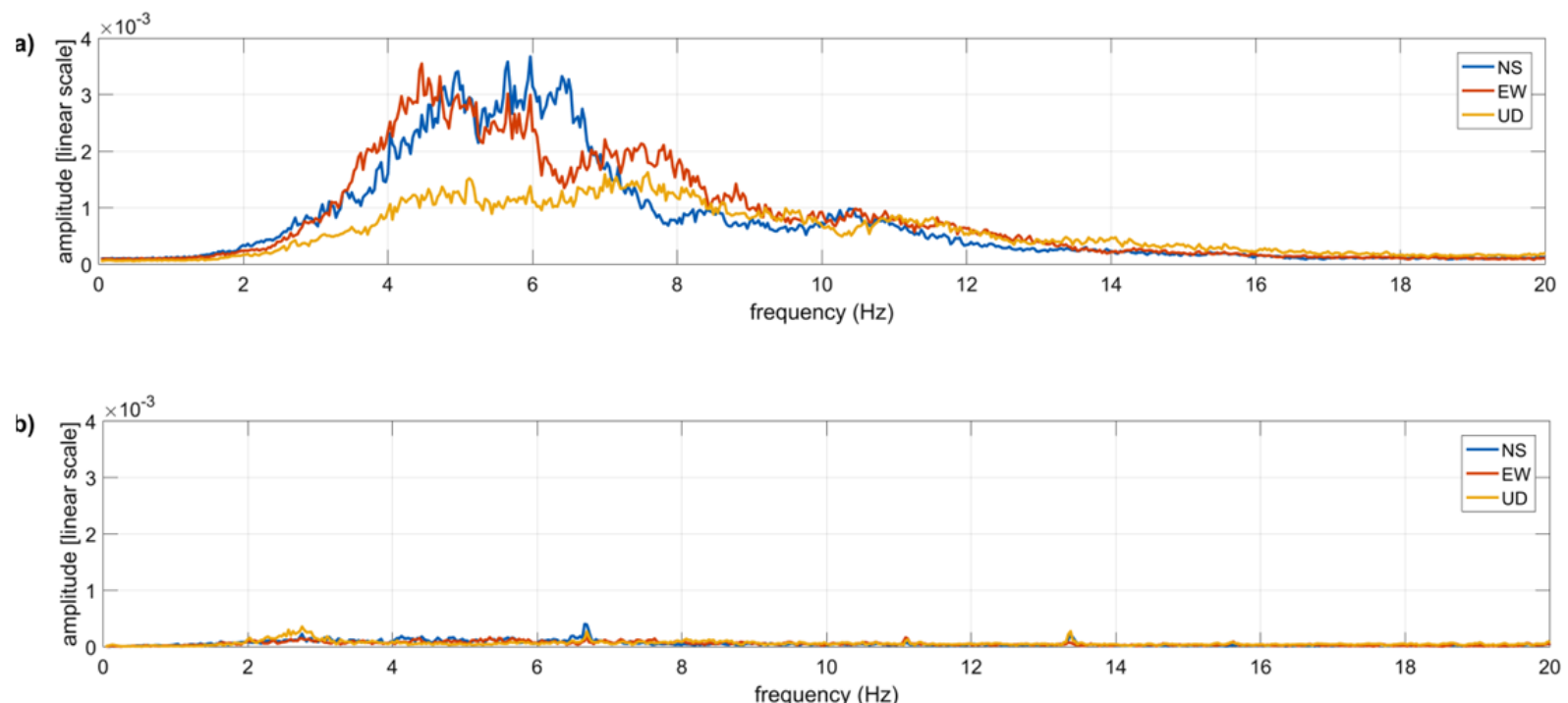

Fig. 14 Amplitude spectra for (a) the raw data and (b) the selected (rectangles in Fig. 13) 1.5 minutes. For the two plots we intentionally adopted the same scales, so to better highlight the influence of the vibrations produced by the excavator. 

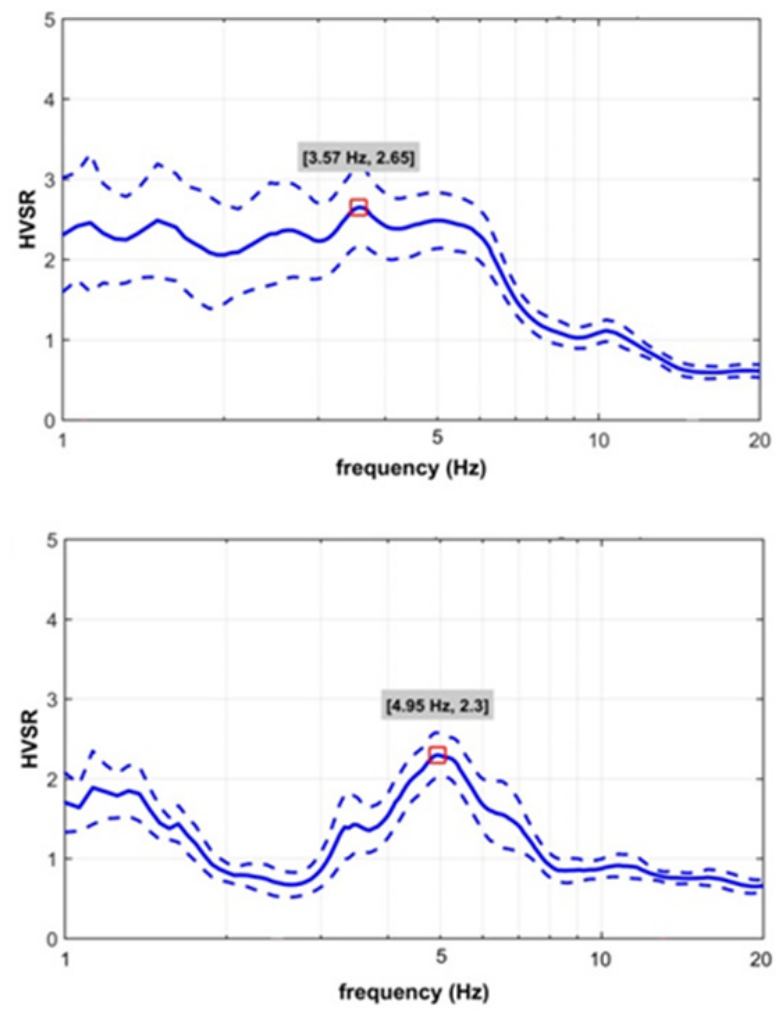

Fig. 15 HVSR curves computed (a) while the excavator was working and (b) considering only the 1.5 minutes highlighted by the two rectangles shown in Figure 13.

\subsection{HVSR PROCESSING AND JOINT INVERSION WITH THE ACTIVE DATA}

In order to classify the site according to the Eurocode 8 (EN 1998-1, 2004), it is necessary to determine the $V_{S}$ values down to $30 \mathrm{~m}$. Since the offset of the active data was not sufficient to reach such a depth, by means of the same $3 \mathrm{C}$ geophone used for the acquisition of the active data we also acquired a passive dataset aimed at defining the HVSR curve (e.g. Fäh et al., 2001). Unfortunately, the excavator working about $40 \mathrm{~m}$ away from the point where we were recording the data introduced a significant amount of artificial vibrations. Figure 13 shows the 16 minute long dataset with clear evidence of the largeamplitude disturbances generated by the excavator. The earthworks temporarily stopped for just about $1.5 \mathrm{~min}$ (see the two rectangles in Fig. 13).

The amplitude spectra of the three components computed considering the entire dataset and just the 1.5 minutes isolated by the two rectangles are shown in Figure 14. Please note that, in order to highlight the influence of the vibrations generated by the excavator, we intentionally kept the same scales for both the plots (Figs. 14a and 14b). We then computed the H/V spectral ratio for both the time series (the raw data and the selected $1.5 \mathrm{~min}$ ) with the results presented in Figure 15. According to the SESAME recommendations (SESAME, 2004) the minimum signal duration necessary for being able to properly determine the HVSR curve down to $2 \mathrm{~Hz}$ is about $1.7 \mathrm{~min}$ (100 s). Nevertheless, being a bit less strict, we can try to keep the retrieved curve down to $1 \mathrm{~Hz}$.

The largest difference in the HVSR curves reported in Figure 15 is clearly in the $1-5 \mathrm{~Hz}$ frequency range.

We then performed the joint inversion of the HVSR curve obtained from the selected data (Fig. 15b) together with the $\mathrm{Z}$ and $\mathrm{R}$ group-velocity spectra (the same used in the previous sections) similarly to the work presented in Dal Moro (2015). Results are summarized in Figure 16 and require some comments.

The peak of the H/V spectral ratio at about $5 \mathrm{~Hz}$ relates to the top of the sands at a depth of about $10 \mathrm{~m}$ (see also the analyses performed with the active data alone) while the abrupt decrease of the $\mathrm{H} / \mathrm{V}$ spectral ratio between about 5 and $2 \mathrm{~Hz}$ (Fig. 15b) is responsible for the low velocity layer (LVL) clearly visible in Fig. 16d between about 18 and $26 \mathrm{~m}$.

Due to the limited offset (just $30 \mathrm{~m}$ ), the active data cannot sense the materials deeper that approximately $15-20 \mathrm{~m}$ (the group-velocity spectra can be used only down to about $4 \mathrm{~Hz}$ ). Therefore, the deeper layers are constrained by the HVSR curve only.

A series of considerations regarding the obtained $\mathrm{V}_{\mathrm{S}}$ profiles and the available geotechnical and borehole data is presented in the following section.

\section{DISCUSSION}

Figure 17 reports the four models obtained according to the four inversion strategies considered for the present work. Due to the limited offset adopted for the acquisition of the active data, the $V_{S}$ profiles for the model\#1, 2 and 3 are sufficiently reliable only down to about $15-20 \mathrm{~m}$ (half or two thirds of the adopted offset). As a consequence, the $V_{S}$ values of the deeper strata obtained for the model\#4 depend only on the $\mathrm{H} / \mathrm{V}$ spectral ratio.

Considered the challenging experimental conditions (limited available room and noisy conditions), the overall general agreement is apparent and the obtained $V_{S}$ profiles can be compared with the available geotechnical and borehole data.

A geotechnical test (CPTU - piezocone penetration test) performed in the area (point $\mathrm{P}$ in Fig. 3) reached a depth of about $16 \mathrm{~m}$ (the tip resistance $\mathrm{q}_{\mathrm{c}}$ values are presented in Fig. 18a). CPTU data are commonly used to infer geological information and geotechnical characterization by means of empirical relationship that tries to establish a link between the cone resistance and a series of geotechnical parameters as well as the Vs values (Hegazy and Maine, 1995; Madiai and Simoni, 2004; Andrus et al., 2007; Monaco et al., 2012; Robertson, 2012).

Penetrometer data are representative of very local conditions and, because of possible lateral variations, they are not necessarily representative of the whole area, even if in this area we do not expect major and dramatic lateral variations. All the correlations to estimate the shear-wave velocities proposed in literature are controlled by parameters like geological age, degree of cementation, soil type, confining stress, depth etc. and several empirical relationships have been proposed. 
a)

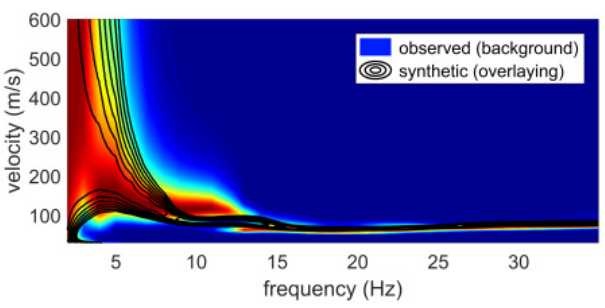

b)

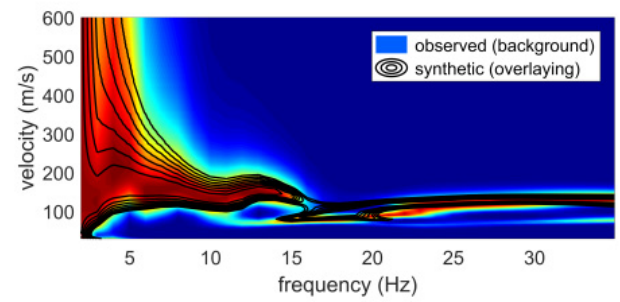

c)

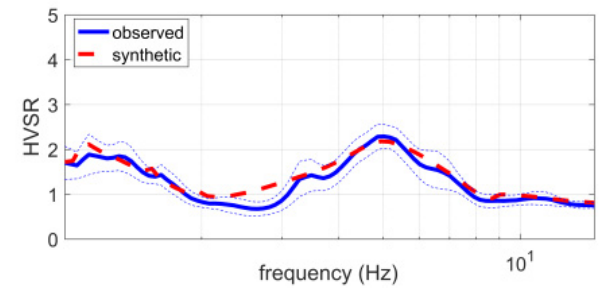

d)

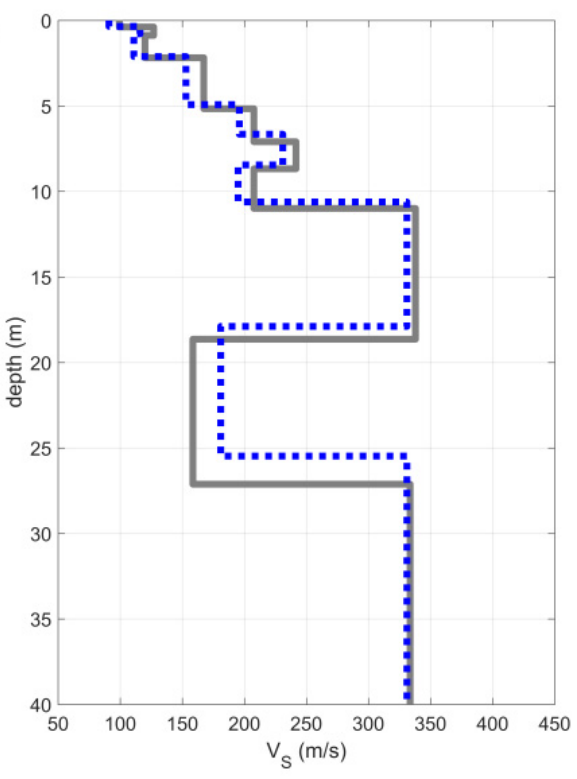

Fig. 16 Result of the joint analysis of the vertical (a) and radial (b) group-velocity spectra (from active seismics) and the HVSR curve (c). Similarly to the previous figures, the two $\mathrm{V}_{\mathrm{S}}$ profiles reported in $\mathrm{d}$ ) refer to the mean (dotted line) and minimum-distance (continuous line) models [the synthetic data presented in the first three plots refer to the minimum-distance model].

In order to evaluate the reliability of one of these relationships, we considered the equation proposed by Madiai and Simoni (2004):

$\mathbf{V}_{\mathbf{s}}=\boldsymbol{\alpha} \mathbf{q}_{\mathbf{c}}^{\mathbf{\beta}} f r^{\gamma}$

where $\mathrm{q}_{\mathrm{c}}$ is the cone tip resistance, $f r$ the friction ratio and $\alpha, \beta$ and $\gamma$ vary according to the ages and mechanical behavior (cohesive, incoherent) (see Table 2).

The $V_{S}$ values obtained using the equation 1 is presented in Figure 18b. While the values of the shallow (clay/silty) materials are not far from those obtained while analyzing the seismic data, the values related to the sandy strata (from about 9 to $16 \mathrm{~m}$ ) appear definitely too large both with respect to the values obtained via seismic-data inversion, both considering the typical values that characterize this sort of sandy sediments (e.g. Dal Moro, 2014).

A slightly-stiffer layer at a depth of about $7 \mathrm{~m}$ seems supported by both the geotechnical and seismic data (compare with Figs. 11, 12b, 16d and 17).

The reliability of the LVL obtained through the joint analysis of the active data and the HVSR curve can be evaluated by considering the information from a borehole about $300 \mathrm{~m}$ from the investigated site (no closer borehole data were available) and reported in Figure 19. The general agreement between the $V_{S}$ profile obtained from the analysis of the seismic data down to $30 \mathrm{~m}$ is apparent. In particular, the clay level between 14 and $26 \mathrm{~m}$ appears consistent with the $V_{S}$ model presented in Figure 16.

\section{CONCLUSIONS}

In the present paper we presented the results of a series of possible inversion procedures aimed at retrieving the $\mathrm{V}_{\mathrm{S}}$ vertical profile while properly exploiting the active and passive data acquired by a single $3 \mathrm{C}$ geophone. In order to avoid dealing with trivial data and ideal conditions, we intentionally considered a site where the space available for the data acquisition was quite limited and the noise level extremely large.

In spite of the limited field equipment and effort, it should be underlined that the adopted procedures allowed analyzing five objects (the $\mathrm{Z}$ and $\mathrm{R}$ groupvelocity spectra, the RPM and RVSR curves and the $\mathrm{H} / \mathrm{V}$ spectral ratio), so to obtain a robust subsurface model confirmed also by the penetrometer and borehole data.

Dispersion data (we considered both the vertical and radial components of Rayleigh waves) were treated according to the FVS approach so to avoid any subjective data interpretation.

Table 2 Parameters reported in Madiai and Simoni (2004) to estimate the $V_{S}$ values from penetrometer data (see eq. 1).

\begin{tabular}{lclc}
\hline Soil behaviour / Age & $\alpha$ & \multicolumn{1}{c}{$\beta$} & $\gamma$ \\
\hline cohesive / Holocene & 140 & 0.3 & -0.13 \\
cohesive / Pleistocene & 182 & 0.33 & -0.02 \\
incoherent / Holocene & 268 & 0.21 & -0.02 \\
incoherent / Pleistocene & 172 & 0.35 & -0.05 \\
\hline
\end{tabular}




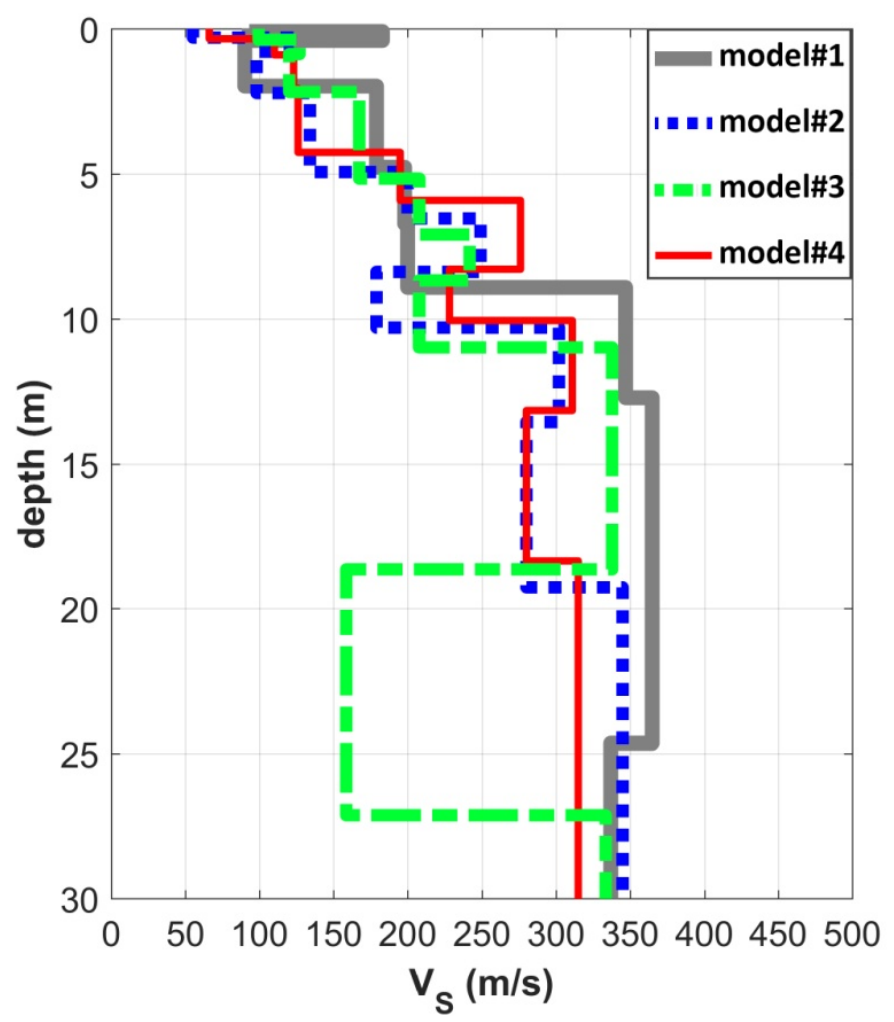

Fig. 17 Comparison of the $V_{S}$ profiles obtained according to the four approaches considered for the present work. Model\#1: minimum-distance model from the joint analysis of the group velocity spectra and the RVSR curve; model\#2: minimum-distance model from the joint analysis of the group velocity spectra and the RPM frequency curve; model\#3: best model from the inversion of the RVF groupvelocity spectrum only; model\#4: minimum-distance model obtained by the joint inversion of the $\mathrm{Z}$ and R group-velocity spectra and the HVSR. See text for comments.

a)

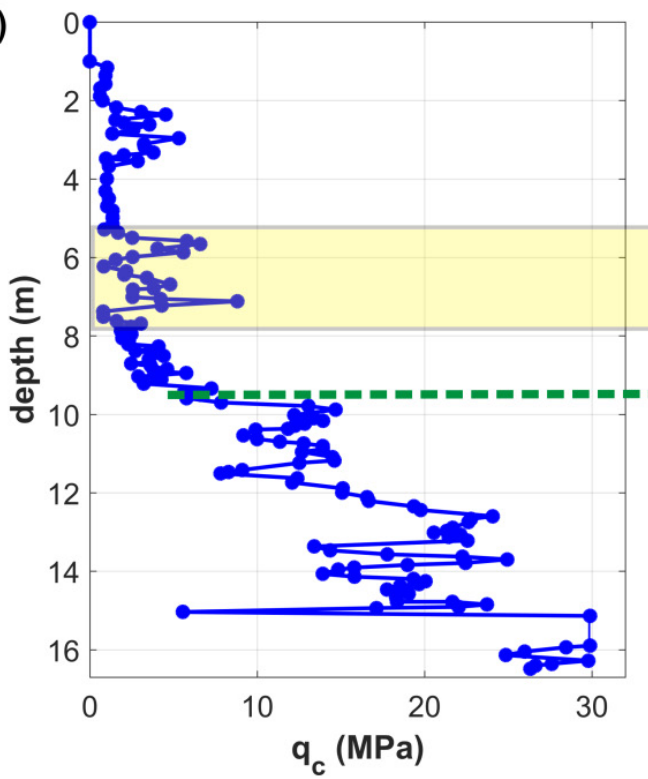

b) 0

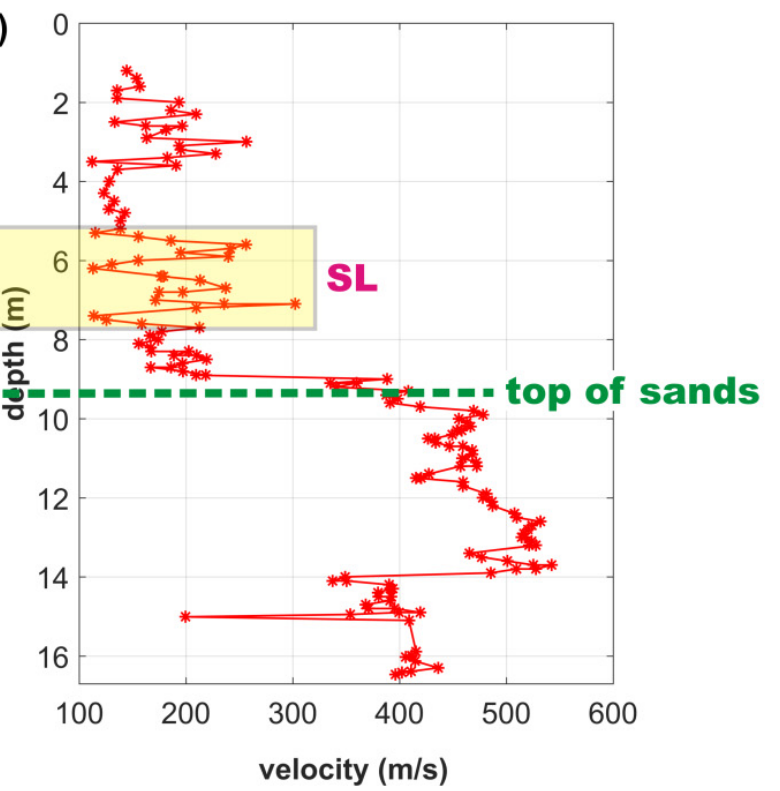

Fig. 18 Penetrometer data: a) $q_{c}$ (cone tip resistance) values from a point about $20 \mathrm{~m}$ away from the midpoint of the HS acquisition line (point $\mathrm{P}$ in Fig. 3); b) $\mathrm{V}_{\mathrm{S}}$ estimated considering the relationship proposed by Madiai and Simoni (2004). 


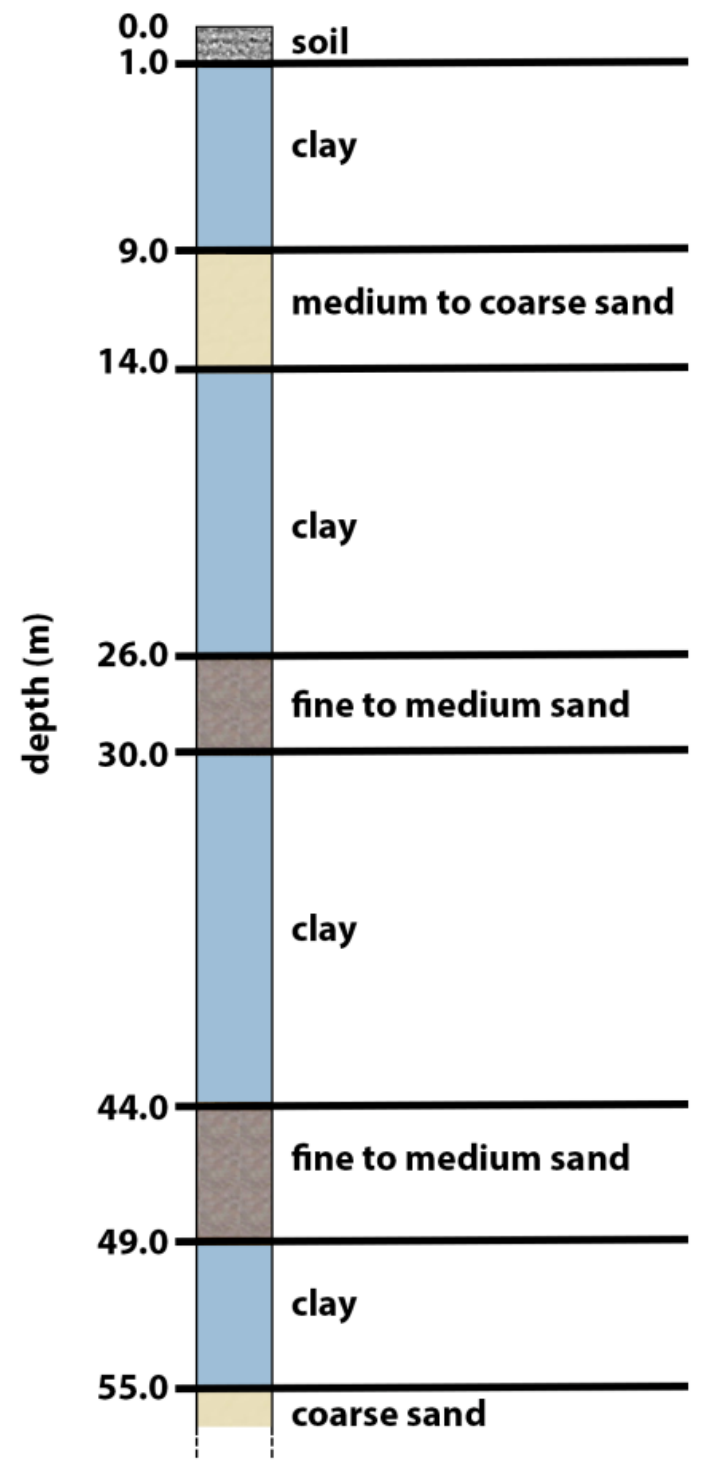

Fig. 19 Stratigraphy from a borehole approximately $300 \mathrm{~m}$ away from the investigated site.

The analysis of the passive data used to determine the $\mathrm{H} / \mathrm{V}$ spectral ratio revealed that in the 1$20 \mathrm{~Hz}$ frequency range the vibrations generated by the excavator were extremely large (Fig. 14).

On the other side, the comparison of the two computed HVSR curves (Fig. 15) have shown that such artificial vibrations altered the $\mathrm{H} / \mathrm{V}$ spectral ratio only in the 1-5 Hz range while at higher frequencies the two HVSR curves appear quite similar (because of the limited length of the clean time series, it is not possible to analyze and compare frequencies lower than about $1 \mathrm{~Hz}$ ).

Through a careful exploitation of the active and passive data collected by a single $3 \mathrm{C}$ geophone we were thus able to depict the $\mathrm{V}_{\mathrm{S}}$ vertical profile in spite of the problematic conditions of the site.

From the stratigraphic point of view, although it is not possible to establish a strict correlation, we can notice that the depth of the sands (about $9 \mathrm{~m}$ ) is the same as for a site investigated at the opposite side of the Grado-Marano lagoon (about $13 \mathrm{~km}$ eastward as the crow flies) and presented in Dal Moro et al. (2015c).

\section{ACKNOWLEDGEMENTS}

This work was partly supported by the Institute of Rock Structure and Mechanics (Czech Academy of Sciences - Prague, CZ), Institute grant for the "Extreme Seismics" project supported in the framework of the long-term conceptual development research organization (RVO: 67985891). The authors would like to express their gratitude to Roberto Ponta for the permission to publish the data and to two anonymous reviewers whose constructive comments significantly helped in improving the overall manuscript.

\section{REFERENCES}

Andrus, R.D., Mohanan, N.P., Piratheepan, P., Ellis, B.S. and Holzer, T.L.: 2007, Predicting shear-wave velocity from cone penetration resistance. Proceedings of the 4th International Conference on Earthquake Geotechnical Engineering. Thessaloniki, Greece.

Bertram, M.B. and Margrave, G.F.: 2011, Recovery of low frequency data from $10 \mathrm{~Hz}$ geophones. Proceedings of the CSEG Recovery 2011 meeting, Canadian Society of Exploration Geophysicists, Calgary, May 2011. Available on-line:

https://www.crewes.org/ForOurSponsors/ResearchRe ports/2010/CRR201008.pdf

Coello Coello, C.A.: 2003, Guest editorial: special issue on evolutionary multiobjective optimization. IEEE Transactions on Evolutionary Computation, 7, 2, 9799. DOI: $10.1109 /$ TEVC. 2003.810762

Dal Moro, G., Moustafa, S.R. and Al-Arifi, N.S.: 2017a, Improved holistic analysis of Rayleigh waves for single- and multi-offset data: Joint inversion of Rayleigh-wave particle potion and vertical- and radialcomponent velocity spectra. Pure and Applied Geophysics, in press

Dal Moro, G., Al-Arifi, N.S. and Moustafa, S.S.R.: 2017b, Analysis of Rayleigh-wave particle motion from active seismics. Bull. Seism. Soc. Am., 107, 1, 51-62. DOI: $10.1785 / 0120160063$

Dal Moro, G.: 2016, Four geophones for seven objective functions: active and passive seismics for tricky areas. Invited presentation and Extended Abstract for the Urban Geophysics workshop at the 22nd EAGE Near Surface Geoscience Conference (Barcelona - Spain, 48 September 2016).

Dal Moro, G., Keller, L., Al-Arifi, N.S. and Moustafa, S.S.R.: 2016, Shear-wave velocity profiling according to three alternative approaches: a comparative case study. J. Appl. Geophys., 134, 112-124. DOI: 10.1016/j.jappgeo.2016.08.011

Dal Moro, G., Keller, L. and Poggi, V.: 2015d, A comprehensive seismic characterization via multicomponent analysis of active and passive data. First Break, 33, 9, 45-53. DOI: $10.3997 / 1365-2397.2015004$

Dal Moro, G., Ponta, R. and Mauro, R.: 2015c, Unconventional optimized surface wave acquisition and analysis: Comparative tests in a Perilagoon Area. J. Appl. Geophys., 114, 158-167. DOI: $10.1016 /$ j.jappgeo.2014.12.016

Dal Moro, G., Moustafa, S.S.R. and Al-Arifi, N.S.: 2015b, Efficient acquisition and holistic analysis of Rayleigh 
waves. Proceedings of the Near-Surface EAGE 2015 Congress (Turin - Italy, 6-10 September 2015).

Dal Moro, G., Moura, R.M. and Moustafa, S.S.R.: 2015a, Multi-component joint analysis of surface waves. J. Appl. Geophys., 119, 128-138.

DOI: $10.1016 /$ j.jappgeo.2015.05.014

Dal Moro, G.: 2015, Joint inversion of Rayleigh-wave dispersion and HVSR of lunar seismic data from the Apollo 14 and 16 sites. Icarus, 254, 338-349. DOI: $10.1016 /$ j.icarus.2015.03.017

Dal Moro, G.: 2014, Surface wave analysis for near surface applications. Elsevier, ISBN 9780128007709, 252 pp.

Dal Moro, G., Coviello, V. and Del Carlo, G.: 2014, Shearwave velocity reconstruction via unconventional joint analysis of seismic data: Two case studies in the light of some theoretical aspects. In: Engineering Geology for Society and Territory, 5, Springer Int. Publ., 11771182. DOI: $10.1007 / 978-3-319-09048-1225$

Dal Moro, G. and Ferigo, F.: 2011, Joint analysis of Rayleigh- and Love-wave dispersion for near-surface studies: Issues, criteria and Improvements. J. Appl. Geophys., 75, 3, 573-589. DOI: 10.1016/j.jappgeo.2011.09.008

Dal Moro, G., Pipan, M. and Gabrielli, P.: 2007, Rayleigh wave dispersion curve inversion via genetic algorithms and marginal posterior probability density estimation. J. Appl. Geophys., 61, 1, 39-55. DOI: $10.1016 /$ j.jappgeo.2006.04.002

Dal Moro, G. and Pipan, M.: 2007, Joint inversion of surface wave dispersion curves and reflection travel times via multi-objective evolutionary algorithms. J. Appl. Geophys., 61, 1, 56-81. DOI: $10.1016 /$ j.jappgeo.2006.04.001

Dziewonsky, A., Bloch, S. and Landisman, N.: 1969, A technique for the analysis of transient seismic signals. Bull. Seism. Soc. Am., 59, 427-444.

Hegazy, Y.A., and Mayne, P.W.: 1995, Statistical correlations between Vs and CPT data for different soil types. Proceedings, Symposium on Cone Penetration Testing (CPT'95), Swedish Geotechnical Society Linköping, 2, 173-178.

EN 1998-1 (2004) Eurocode 8: Design of structures for earthquake resistance- Part 1: General rules, seismic actions and rules for buildings. On line document: $\mathrm{http}: / /$ eurocodes.jrc.ec.europa.eu/showpage.php?id=138

Fäh, D., Kind, F. and Giardini, D.: 2001, A theoretical investigation of average $\mathrm{H} / \mathrm{V}$ ratios. Geophys. J. Int., $145,2,535-549$. DOI: $10.1046 / j .0956-540 x .2001 .01406 . x$

Madiai, C. and Simoni, G.: 2004, Shear wave velocitypenetration resistance correlation for Holocene and Pleistocene soils of an area in central Italy. Proceedings, 2th International Conference on Geotechnical Site Characterization (ISC'2), Porto, Portugal.

Malischewsky, P.G., Scherbaum, F., Lomnitz, C., Tuan, T. ., Wuttke, F. and Shamir, G.: 2008, The domain of existence of prograde Rayleigh-wave particle motion for simple models. Wave Motion, 45, 4, 556-564. DOI: $10.1016 /$ j.wavemoti.2007.11.004

Monaco, P., Amoroso, S., Marchetti, D., Totani, G., Simonini, P. and Cola, S.: 2012, Stress history of Venice Lagoon sands from DMT and CPTU. Proceedings, $4^{\text {th }}$ International Conference on Geotechnical and Geophysical Site Characterization (ISC'4), Porto de Galinhas, Pernambuco, Brazil, September.
Park, C.B., Miller, R.D. and Xia, J.: 1999, Multichannel analysis of surface waves. Geophysics, 64, 3, 800808.

Park, C.B., Xia, J. and Miller, R.D.: 1998, Imaging dispersion curves of surface waves on multi-channel record. 68th Ann. Internat. Mtg., Soc. Exp 1. Geophys., Expanded Abstracts, 1377-1380.

Robertson, P.K.: 2012, Interpretation of in-situ tests-some insights. Mitchell Lecture. Proceedings, $4^{\text {th }}$ International Conference on Geotechnical and Geophysical Site Characterization (ISC'4), Porto de Galinhas, Pernambuco, Brazil.

Rodríguez-Castellanos, A., Sanchez-Sesma, F.J., Luzón, F. and Martin, R.: 2006, Multiple scattering of elastic waves by subsurface fractures and cavities. Bull. Seism. Soc. Am., 96, 4A, 1359-1374. DOI: $10.1785 / 0120040138$

Safani, J., O’Neill, A., Matsuoka, T. and Sanada, Y.: 2005, Applications of Love wave dispersion for improved shear-wave velocity imaging. J. Environ. Eng. Geophys., 10, 135-150. DOI: 10.2113/JEEG10.2.135

Sawaragi, Y., Nakayama, H. and Tamino, T.: 1985, Theory of multiobjective optimization. Academic Press, 296 $\mathrm{pp}$.

SESAME Project- Site EffectS assessment using AMbient Excitations, 2004. European Commission -Research General Directorate Project No. EVG1-CT- 200000026. Deliverable 23.12 Guidelines for the implementation of the $\mathrm{H} / \mathrm{V}$ spectral ratio technique on ambient vibrations: measurements, processing and interpretation

Tanimoto, T. and Rivera, L.: 2005, Prograde Rayleigh wave motion. Geophys. J. Int., 162, 2, 399-405. DOI: $10.1111 / \mathrm{j} .1365-246 X .2005 .02481 . x$

Xia, J.: 2014, Estimation of near-surface shear-wave velocities and quality factors using multichannel analysis of surface-wave methods. J. Appl. Geophys., 103, 140-151. DOI: 10.1016/j.jappgeo.2014.01.016

Xia, J., Xu, Y., Luo, Y., Miller, R.D., Cakir, R. and Zeng, C.: 2012, Advantages of using multichannel analysis of Love waves (MALW) to estimate near-surface shear-wave velocity. Surv. Geophys., 33, 5, 841-860. DOI: 10.1007/s10712-012-9174-2

Xia, J., Miller, R.D. and Park, C.B.: 1999, Estimation of near-surface shear-wave velocity by inversion of Rayleigh wave. Geophys., 64, 3, 691-700. DOI: 10.1190/1.1444578

Van Veldhuizen, D.A. and Lamont, G.B.: 1998, Evolutionary computation and convergence to a Pareto Front. In: Koza, J.R. (Ed.), Late Breaking Papers at the Genetic Programming 1998 Conference, Stanford University, 221-228.

DOI: $10.1023 / \mathrm{A}: 1015516501242$

Zhang, S.X. and Chan, L.S.: 2003, Possible effects of misidentified mode number on Rayleigh wave inversion. J. Appl. Geophys., 53, 1, 17-29. DOI 10.1016/S0926-9851(03)00014-4

Zitzler, E. and Thiele, L.: 1999, Multiobjective evolutionary algorithms: a comparative case study and the strength Pareto approach. IEEE Trans. Evol. Comput., 3, 4, 257-271. DOI: 10.1109/4235.797969 